\title{
Communications
}

\section{Quantitative Analysis of Chloride by Chlorine-35 NMR Spectroscopy}

\author{
Heon-Sung Lim and Sueg-Geun Lee* \\ Center for Chemical Analysis, Korea Research Institute of Chemical Technology, P.O. Box 107, Yustung, \\ Daejeon 305-606, Korea. "E-mail: leesg@krict.re.kr \\ Received May 15, 2006
}

Key Words : Chloride, Quantitative analysis, Chlorine-35 NMR

While providing the most important information on the structures and dynamics unattainable by other instruments, nuclear magnetic resonance (NMR) spectroscopy method in quantitative analysis was the most unpopular method because of the inherent low sensitivity. However, emerging techniques to improve the sensitivity and high field NMR enable the NMR method to be used as one of the primary analytical method during the last few years. Although its applications are generally limited to the use of hydrogen nucleus, ${ }^{1}$ we recently reported that some of the heteronuclear NMR methods including phosphorus and sodium are either comparable or superior to that of the conventional methods in the field of accuracy and precision. ${ }^{2.3}$ Especially the advantages of this NMR method over the other methods are the selectivity and the simplicity of procedure.

In continuing study of heteronuclear NMR application in quantitative analysis, we attempted the analysis of chloride in solution because chloride is also one of the most frequently analyzed elements in various field of science as a unique versatile probe, even been a determinant for the diagnosis of human cystic fibrosis. ${ }^{6}$ The quantitative analysis of chloride can be done by many different methods such as gravimetric, coulometric, titrimetric, colorimetric, ion chromatographic, and etc, ${ }^{T, 8}$ these methods, however, could have several matrix effect which disturb to get correct analysis results.

This communication will describe a new quantitative analysis of chloride by chlorine-35 NMR which is relatively simple and easy to implement in comparison with the other analytical methods. Because of the natural abundance (chlorine-35 $=75.5 \%$ ) and short relaxation time caused by quadrupole, chlorine-35 is also a very amenable nucleus to measure NMR signal. ${ }^{10}$ With this approach, we could easily analyze the chloride in several different matrices in the range of 20 to $5000 \mu \mathrm{g} / \mathrm{mL}$.

NMR spectra were obtained using Bruker AVANCE-700 spectrometer at $68.61 \mathrm{MHz}$ equipped with $5 \mathrm{~mm}$ broad band probe at $23{ }^{\circ} \mathrm{C}$. The spectra were collected with $0.2 \mathrm{~s}$ relaxation delay, $0.35 \mathrm{~s}$ acquisition time and $8 \mathrm{~K}$ data points over $11800 \mathrm{~Hz}$ spectral width using a $90^{\circ}$ pulse. Because of the fast pulsing due to the quadrupole relaxation of chlorine $(\mathrm{I}=3 / 2)$, the total acquisition time of each experiment
(NS=512) was only about $5 \mathrm{~min}$ to get reasonable signal-tonoise ratio depending on the sample concentration. For the external reference, $0.01(350 \mu \mathrm{g} / \mathrm{mL}), 0.025$, and $0.05 \mathrm{M}$ tetraethylammonium chloride (TEAC) in $99.9 \% \mathrm{DMSO}_{\mathrm{d}} \mathrm{d}_{6}$ were prepared and sealed in a $3 \mathrm{~mm}$ tubes. Each tube was co-axially placed in a $5 \mathrm{~mm}$ NMR tube which contains 20 $5000 \mu \mathrm{g} / \mathrm{mL}$ sodium chloride solution. TEAC $(0.01 \mathrm{M})$ spectrum was referenced $(\delta=67.1 \mathrm{ppm})$ to external sodium chloride $(0.1 \mathrm{M})$ in water:

The representative chlorine-35 NMR spectra of sodium chloride at various concentrations with $0.01 \mathrm{M}$ extemal reference TEAC in DMSO- $\mathrm{d}_{6}$ are shown in Figure 1. The peak ( $\delta=67.1 \mathrm{ppm}$ and the line width $=7 \mathrm{~Hz}$ ) shown with same intensity in all spectra $(\mathrm{A}-\mathrm{I})$ is the peak of $0.01 \mathrm{M}$ TEAC in co-axially placed $3 \mathrm{~mm}$ tube.

The chlorine-35 peak integration ratio of individual sample to the three different external references, $0.01,0.025$. and $0.05 \mathrm{M} \mathrm{TEAC}$, showed the excellent linear regression coefficients ( $\mathrm{R}>0.9997$ ) in the range of 20 to $5000 \mu \mathrm{g} / \mathrm{mL}$ chloride concentration (Figure 2). Although we only showed $20 \mu \mathrm{g} / \mathrm{mL}$ detection with $5 \mathrm{~min}$ acquisition time, detection limit can easily be lowered by increasing number of

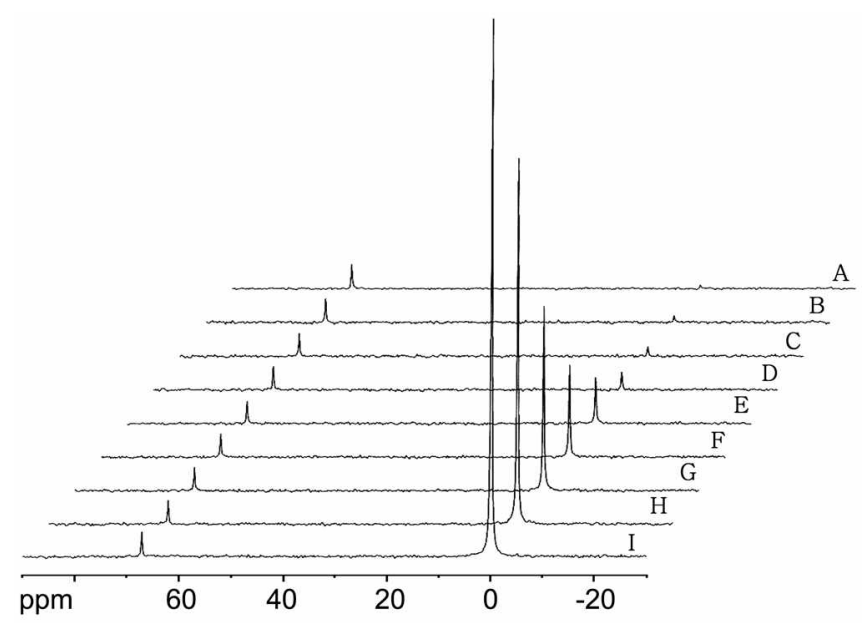

Figure 1. $A$ stack plot of chlorine-35 NMR spectra at various concentrations with $0.0 \mathrm{I} \mathrm{M}(350 \mu \mathrm{g} / \mathrm{mL}$ Cl $)$ TE $\Lambda C$ in DMSO-d 6 as an external reference. The $\mathrm{Cl}$ concentrations (A-I) are $20,30,50$, $100,250,500,1000,2000,3000 \mathrm{~kg} / \mathrm{mL}$. 


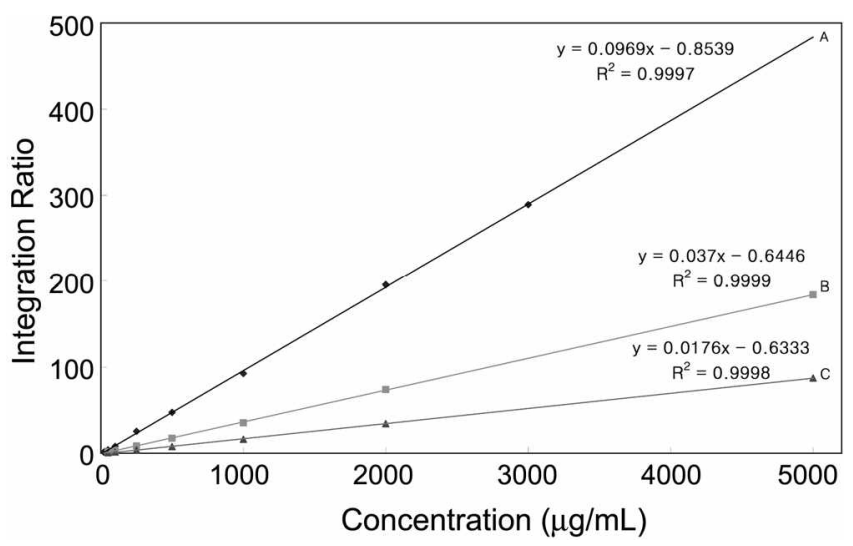

Figure 2. Calibration for $20-5000 \mu \mathrm{g} / \mathrm{mL}$ chloride (NaCl) on various concentration of external references by chlorine-35 NMR spectra [TEAC in DMSO- $\mathrm{d}_{6}$ contained in coaxial tube $=\mathrm{A}: 0.01 \mathrm{M}$, B: $0.025 \mathrm{M}, \mathrm{C}: 0.05 \mathrm{M}$ ].

acquisition with lowering external reference concentration. In addition to showing good solvent effect on chemical shift of chlorine-35, ${ }^{11}$ the extemal reference TEAC in DMSO- $\mathrm{d}_{6}$ showed that the line width was decreased while the chemical shift was moved to downfield further with lowering concentration $\left(0.4 \mathrm{M} ; v_{1 / 2}, 40 \mathrm{~Hz}\right.$ and $\delta, 62.1 \mathrm{ppm}, 0.1 \mathrm{M}$; $v_{1 / 2}, 17 \mathrm{~Hz}$ and $\left.\delta, 65.5 \mathrm{ppm}\right)$.

This high dynamic range detection between the sample and the external reference could have many advantages over the other methods to avoid experimental errors followed by the sample dilution procedures and to analyze complex matrix sample because of selectivity.

We have used these NMR methods with the above calibration results to analyze three known amounts of chloride samples containing several other ions and acid and the results were compared with analysis of ion chromatography. Relative standard deviations and relative percent accuracy of NMR experiments were less than $5 \%$. Especially, in the case of the sample containing high concentration of other matrices, the NMR experiments showed much better results than that of ion chromatography: $150 \mu \mathrm{g} / \mathrm{mL}$ chloride in six other anions ( $2000 \mu \mathrm{g} / \mathrm{mL}$, respectively), the result of ion chromatography was only $51 \mu \mathrm{g} / \mathrm{mL}$ while the result of NMR experiment showed $143 \mu \mathrm{g} / \mathrm{mL}$.

In conclusion, the NMR method mentioned above could be the other standard method of chloride analysis with the merits of the accuracy, selectivity, and simplicity of procedure.

Acknowledgement. This work was supported by KRICT Research Fund (IS-050I).

\section{References}

I. Mendham, J.; Denney, R. C.; Barnes, J. D.; Thomas, M. J. K. In Vogel s' Quantitative Chemical Analysis, 6th ed.; Prentice Hall: England, 2000; Chap. 14 and references cited therein.

2. Ahn, T.-H.; Kang H.-C.; Lee, S.-G. Bull. Korean Chem. Soc. 1992, 13,577 .

3. Lim, H.-S.; Han. G.-C.; Lee. S.-G. Bull. Korean Chent. Soc. 2002. 23,1507 .

4. Biesaga, M.; Schmidt, N.; Seubert, A. J. Chroniatogr. A 2004, $1026,195$.

5. Vanatla, L. E.; Coleman, D. E.; Woodruff, A. J. Chromatogr: A 2003, 997, 195 and references ciled therein.

6. Hukelmann, M.; Oster, O. Clinica Chimica Acta 2002, 319, 75 and references cited therein.

7. Williams. W. J. Handbook of Anion Deternination; Butterworths: London, 1979.

8. Boltz, D. F.; Howell, J. A. Chemical Anah;sis, 2nd ed.; John Wiley and Sons: USA, 1978; Vol. 8.

9. Sulcek, Z; Povondra. P. Methods of Deconposition in Inorganic Antabsis; CRC Press: FL, 1989.

10. Akitt, J. W. In Multinuclear NMR; Mason, J., Ed.; Plenum Press: New York, 1987; Chap. 7.

11. Yudasaka, M.; Sugawara, T.; Iwamura, H.; Fujiyama, T. Bill. Chem. Soc, Jpn. 1982, 55, 311 . 